\title{
Using Insulin Glargine Temporarily to Control Resistant Hyperglycemia Induced by Mild to Moderate Bacterial Infections in Egyptian Type 2 Diabetic Out Patients: A Real Life Experience
}

\section{Mina T Kelleni*}

Department of Pharmacology, College of Medicine, Al Jouf University, Sakaka, Kingdom of Saudi Arabia

*Corresponding author: Mina T. Kelleni, Department of Pharmacology, College of Medicine, Al Jouf University, Sakaka, Kingdom of Saudi Arabia Tel: +201200382422 E-mail: mina.kelleni@mu.edu.eg

Rec date: Feb 03, 2018; Acc date: Feb 12, 2018; Pub date: Feb 19, 2018

Copyright: @ 2018 Kelleni MT. this is an open-access article distributed under the terms of the Creative Commons Attribution License, which permits unrestricted use, distribution, and reproduction in any medium, provided the original author and source are credited.

Citation: Kelleni MT (2018) Using Insulin Glargine Temporarily to Control Resistant Hyperglycemia Induced by Mild to Moderate Bacterial Infections in Egyptian Type 2 Diabetic Out Patients: A Real Life Experience. Gen Med (Los Angeles) 6: e116. doi:10.4172/2327-5146.1000e116

\section{Editorial}

Uncontrolled hyperglycemia favors immune dysfunction and impaired host defenses, including decreased polymorphonuclear leukocyte mobilization, chemotaxis, and phagocytic activity as well as depression of the antioxidant system and is well known to be associated with increased infection risk. Thus, its logic to notice that infectious diseases, affecting all organs and systems, are more frequent and/or serious in patients suffering from diabetes mellitus leading to a significant increase in their morbimortality and some of these problems are seen mostly in diabetic people, such as foot infections, malignant external otitis, rhinocerebral mucormycosis, and gangrenous cholecystitis $[1,2]$. On the other side, it's also well known that acute infections lead to difficulty in controlling blood sugar levels and that infection is the most frequently documented cause of ketoacidosis [3].

The use of intensive insulin therapy to maintain tight control over hyperglycemia, via improvement of the immune response, is highly recommended to decrease infection related morbidity and mortality in critically ill surgical patients [1]. However, many type 2 diabetic Egyptian out patients suffering from hyperglycemia that failed optimized metformin and sulphonylurea combination therapy after mild to moderate bacterial infection refuse to receive the cheaper twice daily syringe injections of biphasic isophane insulin 30/70 even temporarily due to psychological stigma that is, unfortunately, stuck with the usage of this type of insulin therapy in the mind of millions of type 2 diabetic patients in Egypt and perhaps many other developing countries. After taking their consent and assuring that the patients would continue the full course of the prescribed antibiotic which couldn't resolve the infection at the time of the examination, I've decided to try an added on once daily dose of the pen filled preparation of insulin glargine. I've followed every patient on a daily basis and the clinical outcome was very favorable; controlling the blood glucose level and healing from the bacterial infection.

It was previously shown that insulin glargine added to metformin and sulphonylurea therapy in Type 2 diabetes has reduced HbA1c level though on the expense of higher incidence of hypoglycemia and weight gain [4]; complications that weren't encountered with my patients perhaps due to usage of a low dose in their regimen as well as its temporary usage. Further, a once daily insulin glargine regimen was preferred over sliding scale regular insulin in the hospital management of patients with type 2 diabetes mellitus undergoing general surgery [5].

It was once noted that the optimal treatment of hyperglycemia in general surgical patients with type 2 diabetes mellitus was not known [5] and I believe the same applies to the management of type 2 diabetes out patients suffering from mild to moderate infections and I wish this editorial helps to step forward towards this noble aim. I also believe that this regimen may be suitable for a vast majority of type 2 diabetes out patients suffering from infection induced resistant hyperglycemia.

However, I don't recommend usage of the regimen described in this editorial in case of moderate to severe bacterial infections or with critically ill patients who should be hospitalized to receive the appropriate management.

\section{References}

1. Butler SO, Btaiche IF, Alaniz C (2005) Relationship between hyperglycemia and infection in critically ill patients. Pharmacotherapy 25: 963-976.

2. Casqueiro J, Casqueiro J, Alves C (2012) Infections in patients with diabetes mellitus: A review of pathogenesis. Indian J Endocrinol Metab 1: 27-36.

3. Rayfield EJ, Ault MJ, Keusch GT, Brothers MJ, Nechemias C, et al. (1982) Infection and diabetes: The case for glucose control. Am J Med 72: 439-450.

4. Mearns ES, Saulsberry WJ, White CM, Kohn CG, Lemieux S, et al. (2015) Efficacy and safety of antihyperglycaemic drug regimens added to metformin and sulphonylurea therapy in Type 2 diabetes: A network metaanalysis. Diabet Med 32: 1530-1540.

5. Umpierrez GE, Smiley D, Jacobs S, Peng L, Temponi A, et al. (2011) Randomized study of basal-bolus insulin therapy in the inpatient management of patients with type 2 diabetes undergoing general surgery (RABBIT 2 surgery). Diabetes Care 34: 256-261. 